sitated enlargement of the building about twenty-five years ago, when a large hall was added. This is a quadrangular structure eighty-six feet by forty-three feet, with a ground floor and two galleries connected by two spiral staircases, and lighted by forty-eight window's. A second hall of the same dimensions has just been completed, and will soon be occupied. It is connected with the old hall on each floor by a corridor fiftysix feet long, and the floors and roof are of concrete, anu it is intended to replace those of the old hall with the same material at once. It is estimated that the entire collection comprises considerably more than 2,000,000 specimens, attached to I, 300,000 sheets.

With the exception of Carey's North American herbarium, Lindley's orchids, and Borrer and Watson's British herbaria, the plants from all parts of the world are arranged in one series, the genera according to Bentham and Hooker's " Genera Plantarum," and the species geographically. It is unnecessary to enlarge on the value of a herbarium containing the types of all the colonial floras and other works issued from Kew-it is known to all botanists. The library, which the present director has made his special care, is one of the richest, even if not the richest, in existence, and is in admirable condition. It comprises upwards o? 20,000 volumes, besides about ro,ooo pamphlets. The Government published a catalogue of the books in 1899 , and annual supplements since. There is also a separate collection of about I0o, ooo published figures and original drawings of plants.

\section{Borting Hemsley.}

\section{THE SOUTH AFRICAN ASSOCIATION.}

$T$ HE inauguration of the South African Association for the Advancement of Science took place at Cape Town on April 27. The Cape limes, to which we are indebted for the details of the proceedings, describes the successful gathering as a British Association meeting in miniature. The new Association enters upon its career with a membership of seven hundred persons from many parts of South Africa.

The main objects of the organisation are the same as those of the parent body. As defined in the Constitution, they are " to give a stronger impulse and a systematic direction to scientific inquiry; to promote the intercourse of societies and individuals interested in science in different parts of South Africa; to obtain a more general attention to the objects of pure and applied science, and the removal of any disadvantages of a public kind which may impede its progress."

The presidential address was delivered by Sir I David Gill, K.C.B., the Astronomer Royal for South Africa, who explained the nature of the work which it was hoped the new Association would accomplish. During the course of his able address Sir wavid Gill announced that Lord Kelvin had written that, although in 1905 he will be eighty-one years of age, he intends, if he is as well then as he is now, to accompany the British Association on the visit to South Africa.

The work of the sections began on the second aay of the meeting. The presidential addresses in the various sections were delivered by the following men of science :-

Section A.-Astronomy, Chemistry, Mathematics, Meteorology, and Physics, by Prof. P. D. Hahn; Section B.-Anthropology, Ethnology, Bacteriology, Botany, Geography, Geology, Mineralogy, and Zoology, by Dr. R. Marlotti; and Section C.--Archæology, Education, Mental Science, Philology, Political Economy, Sociology, and Statistics, by Dr. 'Thomas Muir, C.M.G., F.R.S., Director of Education for Cape Colony.

Among the papers read during the course of the meetings the following deserve mention. In Section A, on ferments causing "casse" in wine, by Mr. Raymond Dubois; meteorology in South Africa: a retrospect and prospect, by Mr. C. M. Stewart; close binary systems, by Dr. Alex. W. Roberts; determination of mean temperature, \&c., from observations made at second-order stations on the Table L and, by Mr. J. R. Sutton; some recent work on the discharge of electricity from heated bodies, by Prof. J. C. Beattie.

In Section B, ( 1 ) on the occurrence of an epidemic among the domesticated animals in Mauritius in which Trypanosomata were found in the blood; (2) note on the co-relation of several diseases occurring among animals in South Africa; (3) on the production of a malarial form of South African horse sickness, by Dr. Alex. Edington; the minerals of some South African granites, by Mr. F. P. Mennell; on the classification of the Theriodonts and their allies, by Dr. R. Broom; (r) some morphological and biological observations on the genus Anacampseros; (2) on some stone implements in the Albany Museum, by Dr. S. Schonland.

In Section C, some aspects of South African forestry, by Mr. D. E. Hutchins; dry crushing of ore preparatory to the extraction of gold, by Mr. Franklin White; sewage disposal in Cape Colony, by Mr. J. Edward Fitt.

In Section D, the library system of South Africa in comparison with those of England and America, by Mr. Bertram I. Dyer; iteration as a factor in language, by Prof. W. Ritchie; common sense and examination, by $\mathrm{Mr}$. P. A. Barnett ; Cape Dutch, by Prof: W. S. Logeman; how we get knowledge through our senses, by Rev. Dr. F. C. Kolbe.

The example set by the British Association of arranging for receptions and other social functions to lighten the intellectual fare provided was followed at Cape Town, and the excursions, conversazioni, \&c., were well attended and much appreciated.

\section{THE ROYAL SOCIETY CONVERSAZIONE.}

THE conversazione held at the Royal Society on

Friday last was attended by a large and distinguished company, among the visitors being H.R.H. the Prince of Wales and H.S.H. the Duke of Teck. There were numerous exhibits illustrating progress in various branches of science, several of them being of great interest. Following our usual course, we abridge the particulars given in the descriptive catalogue as to the character and purpose of the objects on view.

Sir William Crookes, F.R.S., exhibited objects illustrating certain properties of the emanations of radium. If a solid piece of radium nitrate is brought near a blende screen, and the surface examined with a pocket lens magnifying about 20 diameters, scintillating spots are seen to be sparsely scattered over the surface. On bringing the radium nearer the screen the scintillations become more numerous and brighter, until when close together the flashes follow each other so quickly that the surface looks like a turbulent luminous sea. A convenient way to show these scintillations is to fit the blende screen at the end of a brass tube with a speck of radium salt in front of it and about a millimetre off, and to have a lens at the other end. Focusing, which must be accurately effected to see the best effects, is done by drawing the lens tube in or out. It is proposed to call this little instrument the "Spinthariscope."

Specimens of brittle gold and photographs illustrating their microstructure were shown by Dr. T. K. Rose. Gold of the British imperial standard, containing $9 . \dot{6}$ per cent. of gold and $8 \cdot 3$ per cent. of copper, is made brittle and unfit for coinage by the presence of minute traces of certain impurities such as tellurium, lead, bismuth, \&c. Similar or even considerably greater quantities of these elements, excepting bismuth, do not affect the ductility of fine gold. The deleterious effects of the impurities are removed by the presence of oxide of copper dissolved in the metal. The changes in the quality of coinage bars are accompanied by profound changes in the microstructure of the metal.

Dr. Morris W. Travers exhibited hydrogen thermometers for measuring low temperatures. The thermometers are of the constant-volume type, and are intended for the 
measurement of temperatures between $0^{\circ}$ and $-253^{\circ} \mathrm{C}$. One is graduated directly in degrees on the hydrogen scale, and can be employed for the direct measurement of low temperatures to within one degree. The other is intended for more accurate measurements.

A new coherer, as applied to wireless telegraphy, was shown by Sir Oliver Lodge, F.R.S., and Dr. Alexander Muirhead. A steel wheel rotates so that its edge touches a pool of mercury through a film of oil. (See Proc. Roy. Soc., March.) This is the coherer, and its decoherence is automatic. A fraction of a volt is used in the detecting circuit, which works a siphon recorder as the receiving instrument. The sending part of a station, including an automatic transmitter and a "buzzer" for carving a steady current into intermittencies, was also shown.

Incandescent oil burners were exhibited by $\mathrm{Mr}$. T. Matthews. These burners have been designed by the exhibitor primarily for use in the Trinity House Lighthouse Service. The intensity of the single mantle burner for flashing lights is r 100 candles, and the consumption of oil one pint per hour; the intensity of the triple mantle burner for fixed and occulting lights is 2700 candles, and the consumption of oil three pints per hour, the flashing point of the oil being in each case from $145^{\circ}$ to $160^{\circ}$ Fahrenheit (close test).

Experiments on controlling and regulating spark discharges, shown by Mr. Alfred Williams, illustrate how the use of a shunt, or of a point and shunt, or of plates of high resistance, so influence the field in a spark gap that the discharges are made more regular and placed more under control for therapeutic and wireless telegraphy purposes.

The "Elasmometer," a new form of interference apparatus for the determination of the elasticity of solid substances, was exhibited by Mr. A. E. 'Tutton, F.R.S The apparatus is designed to measure the amount of bending suffered by a thin plate of the substance investigated, when supported near its ends against a pair of platinumiridium knife-edges, under a weight applied at its centre.

Prof. A. G. Greenhill, F.R.S., showed a gyroscopic pendulum, for lecture experiment. A bicycle wheel is suspended by a prolongation of its axis from a universal joint formed with a hub and its ball-bearings. The wheel is rotated by a stick inserted in the spokes, and projected to illustrate the variety of gyroscopic motion.

Dr. W. Ramsden demonstrated by experiments and illustrated by photomicrographs and specimens, the presence and spontaneous formation of solid membranes upon the free surfaces of certain solutions. $\mathrm{He}$ also showed that solid membranes are present on certain bubbles.

Aërial photographs were shown by the Rev. John $M$. Bacon. Among the pictures was one showing the sea bottom at a depth of ten fathoms photographed from an altitude of 600 feet.

The physical sciences were also represented by the following objects and experiments :-A series of photographs and objects relating to Dr. William Gilbert, of Colchester (I544 I603), author of the treatise "De Magnete," Prof. Silvanus P. Thompson, F.R.S.; a direct vision spectroscope of one kind of glass, and of minimum deviation for any ray in the centre of the field of view, Mr. T. H. Blakesley (see p. $7 \mathrm{r}$ ); apparatus for the detection and estimation of minute quantities of arsenic in beer and brewing materials as recommended by a Departmental Committee of the Board of Inland Revenue, Prof. 'T. E. Thorpe, C.B., For.Sec.R.S. ephelkystika, or tractate curves, and machine for drawing them, Col. Hippisley, C.B., R.E.; (I) gravimetric recording hygrometer, (2) an electrical dewpoint hygrometer, Prof. F. T. Trouton, F.R.S.; Callendar's compensated barometer, Mr. N. Eumorfopoulos; light mirrors, suitable for galvanometers (see p. 72), Mr. W. Watson, F.R.S.; micrometer for measuring screws, made for the British Association Screw Gauge Committee, the Cambridge Scientific Instrument Company; photographs of dust deposits, Dr. W. J. Russell, F.R.S. ; examples of Lippmann's process of photography in colours, Mr. Edwin Edser and Mr. Edgar Senior; an experiment illustrating the conductivity imparted to a vacuum by hot carbon, $\mathrm{Mr}$. O. W. Richardson; a high pressure spark-gap used in connection with an inductor of the Tesla type, and also in connection with a radiator of Hertzian waves, Rev. F. J.
Jervis-Smith, F.R.S.; diagrams illustrating the order and origin of the musical scales, Mr. Joseph Goold.

An artificial horizon attachment to sextants, exhibited by Commander Campbell Hepworth, C.B., consists essentially of a contact maker, operated by a plummet mounted on a sextant, and connected with a galvanic battery. It is so adjusted as to close the circuit and ring a bell when a slit or line on the horizon glass is in alignment with the eye of the observer and the sensible horizon. Observations for latitude and longitude at sea are rendered impossible when the natural horizon is obscured by fog or mist, although sun, moon, or stars may be shining clearly; but with the aid of this instrument the observer may obtain the true altitude of a heavenly body within five minutes of arc.

The Solar Physics Observatory, South Kensington, exhibited (x) photographic comparison of the arc spectra of various samples of dust; (2) curves, illustrating the long period solar and meteorological (rainfall) variations of about thirty-five years; (3) photographs of new curved slit by Hilger. This slit is used at the focus of the second objective of the photo-spectro-heliograph, and is intended for the isolation of the $\mathrm{K}$ (calcium) line in the solar spectrum, Nos. $3 a$ and $b$.

The use of a colour screen in photographing bright stars was illustrated by the Cambridge Observatory. By the use of a yellow spot on a worked glass screen in contact with the sensitive plate, the image of a bright star can be reduced to equality with the images of the comparison stars. It thus becomes possible to apply photography to the determination of the parallaxes of bright stars, which have been dealt with hitherto almost entirely by the heliometer.

The chromospheric spectrum near the South Pole of the Sun was shown by Mr. J. Evershed. Nebular spectra of Nova Persei from May 3, I901, to January 14, 1902, with previous spectra for comparison, were illustrated by $\mathrm{Mr}$ Frank McClean, F.R.S. Other exhibits were :-(I) collimating gun sight for day and night; (2) optical sight for guns and rifles; (3) spherometer of great delicacy, by $\mathrm{Dr}$. A. A. Common, F.R.S.

Methods of disintegrating cells and microorganisms, and of obtaining their intracellular constituents, were shown by Dr. A. Macfadyen and Mr. S. Rowland. In the first method the cells are disintegrated by the violent impact of sand particles in the apparatus exhibited. In the second method the use of extraneous disintegrating material is dispensed with, the cells or organisms being disintegrated when in a frozen condition. In the apparatus exhibited the necessary cold and brittleness are secured by the use of liquid air.

Dr. Leonard Rogers exhibited five specimens of Hydrophidæ (poisonous sea snakes). These snakes swarm round the coasts of India and in other tropical seas, and cause some loss of life among fishermen. Their poison has recently been found to be more powerful than that of any other snakes.

Miss E. R. Saunders illustrated interesting cases of structural atavism resulting from cross-breeding. Experiments (Report Evolution Committee, r902) with stocks suggested that when glabrous plants of dissimilar colours are crossed together, the offspring might be hoary. Actual trials have proved this to be true. When glabrous cream or white are crossed with each other, or with glabrous plants of other colours, the offspring are all hoary; but when colours other than white or cream are crossed together, the offspring are all glabrous.

Fossils in Cambrian quartzite were shown by Prof. J. Norman Collie, F.R.S. These fossils were found on the surface of a glacier in Desolation Valley (near Laggan Railway Station), Canadian Rocky Mountains.

Dr. Henry Woodward, F.R.S., exhibited two photographs of Tetrabelodon (Mastodon) angustidens, Cuvier, from the Miocene of Sansan, France, taken from the skeleton in the Museum of Natural History, Paris. This primitive form of Mastodon still retains two pairs of functional incisor teeth (tusks), one pair in the upper and one pair in the lower jaw, the upper ones being directed downwards. In modern elephants only one pair (the upper) incisors are present, and these are usually curved upwards. (See Dr. C. W. Andrews's paper, Proc. Roy. Soc., No. 474.)

The Royal Geographical Society had on view (I) hypso-

NO. $175 \mathrm{I}$, VOL 687 
metrical and bathymetrical map of the Western Mediterraneall and surrounding countries, curved to show the figure of the earth; (2) relief map of a part of the valley of the Semois in the neighbourhood of Rochepaut, Belgian Ardennes. These maps have been prepared under the direction of Prof. Elisee Reclus by Mr. E. Patesson. The map of the Mediterranean, in aluminium, is drawn on the scale of $1: 5,000,000$. It is curved to show the exact figure of the earth. Elevations of land and depths of water are shown by a system of contours and tinting. The second map is in copper, and represents the relief of the district without exaggeration of the vertical scale, and with the surface features carefully laid down. Both maps are intenced for educational purposes.

Pictures shown by Mr. Arthur J. Evans, F.R.S., illustrated excavations at Knossos, in Crete, and included : (I) general plan of the palace, showing excavations to June, 1902, and general section, showing successive terrace levels, \&c. (2) photographic views; (3) coloured drawings of palace frescoes.

Other exhibits were chloroformed calf lymph; method of its preparation (from the Government Lymph Laboratories), Dr. Alan B. Green; development and variation of the colour-pattern in Mexican species of lizards (Cnemidophorus and Ameiva), Dr. H. Gadow, F.R.S.; (I) true (glandular) hermaphroditism in a domestic fowl; (2) microscopic sections of prehistoric human bone, and of a prehistoric human urinary calculus, Mr. S. G. Shattock. Mimicry in butterflies from British East Africa and Uganda, Mr. S. A. Neave; specimen of Trypanosoma found by Dr. Castellani in cerebro-spinal fluid from sleeping sickness patients (Uganda), Dr. Aldo Castellani; specimens of a remarkable radiolarian of complex structure, Dr. G. H. Fowler; restored models of extinct fishes, the Director, British Museum (Natural History); preparations illustrating the cell-phenomena met with in apogamy, Prof. J. B. Farmer, F.R.S., Mr. J. E. S. Moore, and Miss L. Digby (see p. 7I); remains of pigmy elephant and piginy hippopotamus obtained from caves in Cyprus, Miss Dorothy M. A. Bate (see p. 7I); (I) photographs illustrating the late eruptions in St. Vincent and Martinique ; (2) volcanic dusts, ashes, and other ejecta of the West Indian volcanoes, West Indies Volcanoes Committee of the Royal Society; micrographs of volcanic dust from Mount Soufrière, St. Vincent, eruption, May 8, 1902, Mr. Thomas Andrews, F.R.S.; (I) the experimental demonstration of the curvature of the earth's surface recorded by photography ; (2) photograph of ship hull-down at sea, Mr. H. Yule Oldham.

During the evening lantern demonstrations were given by Sir Benjamin Baker, K.C.B., F.R.S., illustrative of the Nile Dam Works, and by Prof. Harold B. Dixon, F.R.S., on the analysis of explosion flames by photography. The latter demonstration included (I) photographs of explosion flames, taken on very rapidly moving films, showing the genesis of the explosion-wave as the flame travels from the point of ignition, and the influence of reflections from the ends of the tube; (2) photographs of sound-waves moving through the explosion-flame, by which the approximate temperature of the flame may be calculated.

\section{COOPERATION IN ASTRONOMY.}

$T$

$\mathrm{HE}$ suggestions contained in the subjoined extracts from a paper by Prof. E. C. Pickering on "The Endowment of Astronomical Research," recently issued from Harvard College Observatory, will, we hope, be taken up by one of the many generous benefactors of science and higher education in the United States. The fundamental idea is the organisation of the forces which exist for the advancement of knowledge of astronomy. Many gifts have been made to astronomy in the United States, but in some cases the results have been disappointing, because the donors have not consulted astronomers as to the best way to promote scientific advance.

Imposing observatories are useless without instruments, and fine telescopes and spectroscopes depend

NO. 175 I, VOL. 68 ] upon "the man at the eye end" for the return they will give for the expenditure upon them. To obtain the best results, the astronomer with original ideas and progressive spirit should be placed in a position where he can carry on his work to the best advantage, and instruments should be used by men who require them for the increase of knowledge. This is the object of the plan proposed by Prof. Pickering. Money, materials and men available for astronomical research are to be brought together so that each is used to the best advantage.

In the United States, where the liberal benefactor has endowed scientific work to an extent unparalleled in any other country, the scheme will probably be taken up. Though the gifts to higher education and research have been so many and generous in the past, Prof. Pickering remarks that owing to the industrial prosperity of America " gifts may be expected ten times as large as those of the last century, during which Harvard College Observatory received three funds exceeding one, two, and three hundred thousand dollars respectively." He has therefore considered how a gift of one or two million dollars, if given to Harvard for astronomical purposes, could be best expended. The cooperative scheme of work suggested is one which would certainly accelerate progress, and the results attained would be such that enlightened donors could see and appreciate them.

There would be no attempt to interfere with independent work; in fact, the scheme aims at promoting such work and providing for the publication of the results. The Carnegie Institution was established with the same objects, and has already provided the means for carrying on important inquiries in various branches of science. Prof. Pickering's plan is worthy of the broad views associated with Harvard College Observatory, and we trust that means will be forthcoming to carry it into effect. We reprint part of the circular in which the plan is put forward.

The following outline of a plan will show how a sum of fifty to one hundred thousand dollars annually could be advantageously expended for astronomy by this observatory. A board of advisers, consisting of several of the leading astronomers of the country, would be appointed which would meet once a year, or at first oftener, to consider how the available income could be best expended in order to receive the greatest scientific return.

This board would consist partly of the directors of observatories who could expend portions of the income themselves, and partly of older astronomers who, having retired from active work, could decide without prejudice how the income could be expended to the best advantage by others. They would have authority to add temporarily to their number astronomers who might be invited to participate in any special work, and who could thus take part in their discussions on equal terms. All expenses of this board would be paid from the income, and except for clerk hire these would be almost the only executive expenses. A circular letter would be sent to all astronomers, inviting application for aid and suggestions for methods of expending the income. If possible, close relations would be established with the trustees of all the research funds which could be used for astronomical purposes, to increase efficiency and avoid duplication of work. The most important duty of the board of advisers would be to consider each year what departments of astronomy were being neglected, and to secure the needed observations, or if necessary undertake them themselves, or see that they were made at Harvard. As every astronomer is inclined to undertake the work which attracts him most, especially interesting investigations are likely to be duplicated unnecessarily, while laborious or unattractive investigations are neglected. This is particularly objectionable, since in astronomy, a science of observation and not of experiment, an opportunity once missed can in many cases never be recovered. As an example of needless duplication, fifty observatories agreed to observe the planet Eros during its opposition in 1900 , but, so far 